\title{
Impact of Self-consumption and Storage in Low Voltage Distribution Networks: An Economic Outlook
}

\author{
Fernando M. Camilo ${ }^{1}$, Rui Castro ${ }^{1,2}$, M. E. Almeida ${ }^{1,2}$, and V. Fernão Pires ${ }^{2,3}$ \\ ${ }^{1}$ IST, University of Lisbon, \\ 1049-001 Lisbon, Portugal \\ ${ }^{2}$ INESC-ID/IST, University of Lisbon, Lisbon, Portugal \\ ${ }^{3}$ EstSetúbal, Polythecnics of Setúbal, Setúbal, Portugal \\ \{fernando.camilo,rcastro,d2527\}@tecnico.ulisboa.pt \\ vitor.pires@estsetubal.ips.pt
}

\begin{abstract}
A paradigm shift is taking place in Low Voltage (LV) distribution networks, motivated by progressive implementation of renewable microgeneration $(\mu G)$, mainly Photovoltaic (PV), near household consumers. The concept of self-consumption linked to battery storage is emerging as a way to enhance the quality of electrical network. Smart-Grid (SG) environment comes close to this approach and may have a crucial relevance on management of intelligent power distribution networks, in the framework of a Smart Environment. This paper proposes an additional contribution on the subject by investigating the economic profitability of PV battery systems being analyzed with respect to its impact and economic feasibility, taking into consideration their initial investment and operation costs. The purpose is to verify if prosumer's investment is financially more interesting than purchasing all electricity needed for consumption from the LV grid. The results of the performed economic analysis show that self-consumption with storage is a potential solution.
\end{abstract}

Keywords: Micro-Generation, Self-Consumption, Battery Storage, Economic Analysis

\section{Introduction}

Nowadays, a paradigm change is ongoing in LV distribution networks driven by the progressive implementation of renewable $\mu G$ next to the consumers, mainly from small PVs type. This change can bring benefits, mainly in rural areas, as it allows to improve the quality of electrical energy supply [1]. This novel operational model allows to highlight the concept of prosumers (consumers that both produce and consume electricity), considering that this strategy may be interesting both from a technical and economical point of view $[2,3]$. Self-consumption and storage of electricity surplus in batteries during daylight, to be used later when there is no sun power, is being recently adopted as a way to facilitate the integration of more small renewable energy sources in LV distribution networks. The advantages resulting from the im- 
plementation of prosumers in the distribution network, as well as the possibilities for integration of energy storage technologies, can be further enhanced by combining the intelligent power distribution networks or SG $[4,5]$.

The SG concept comes very close to this paradigm change. It is nowadays wellknown that SG can bring benefits in terms of safety, economy and efficiency of the network [6]. Moreover, the evolution of communication and information technologies, is supporting the development of SG and appears as an assimilated vision for the future power systems $[7,8]$.

Nowadays, PV feed-in tariffs incentives are progressively being removed. This can be perceived as a prelude for the promotion of self-consumption. Intense research on economic viability of PV systems have been recently presented. These works intend to validate the viability of PV systems from different perspectives: net-metering and bill savings [9, 10], feed-in tariffs assessment [11, 12], energy policies to support the promotion of PV systems $[13,14]$. As a result, it is now commonly accepted that it is essential to have investment and operating costs information, in order to enable timely planning and on-line buying and selling of electrical energy, bearing in mind the netmetering context [15].

This paper proposes a supplementary contribution on the subject by investigating the economic profitability of PV battery systems. Battery Energy Storage (BES) aims at reducing the electricity consumption from the distribution networks, because residential clients consume and store the energy they produce on their own. PV battery systems are analyzed with respect to its impact and economic feasibility, taking into consideration, their initial investment and operation costs, where the purpose is to verify if the prosumer's investment, is financially more interesting than purchasing all electricity needed for consumption from the LV grid.

\section{Contribution to Cyber-Physical Systems}

Cyber-Physical Systems (CPS) are the new generation of engineering systems that offer close interaction between cyber and physical components [16]. CPS are at the center of current discussions about the next generation of intelligent services, that power areas as diverse as medicine, aerospace, electrical networks, consumer appliances [17]. This approach may be the new vision of the future in several areas of society. The potential investment gains of CPS are immense, inasmuch as the traditional systems can fail in solving problems of physical and computational nature. Continuous advances in science and engineering improve the bond between the computational and physical elements through smart mechanisms, significantly increasing the adaptability, autonomy, efficiency, reliability, security and functionality of cyber-physical systems [18].

The SG concept is connected to the evolution of communication and information technologies, where CPS may be the answer to bring this concept to another level. Some entities, such as the NIST Engineering Laboratory [19], are dedicated to the development of SG study in a CPS context. This approach, from SG perspective, can bring many benefits in terms of safety, economy, efficiency and reliability [20,21]. 
Classical SG example are the smart-meters, in which is possible through CPS, monitor and manage the power of the smart house. On another scale, in theory, the aim of CPS is not only managing and monitor the smart house but manage and monitor the entire electrical network as a whole. In sequence of this management through CPS, the net-metering system can be applied. Net-metering is based on the concept that the surplus production and injected into the network is recorded as credits, that can be compensated for consumption, in greater time period, using the grid as a longterm storage [13]. An alternative would be to manage the power grid with the possibility of using the batteries of residential prosumers, if required, by the power grid. The CPS, in this case, could manage and use energy from these batteries, bridging any gaps of the network. In this case, there would be a compensation to the prosumer, credited for the energy used in this process, similar to net-metering, where CPS could be an excellent contribution, allowing the optimization of management of the entire electrical system.

Is essential to have a knowledge of the investment and operating costs, in order to enable timely planning and, considering the net-metering context, the on-line buying and selling of electricity. In future, the storage system can be fundamental, in electricity sales perspective by credits, in which CPS may reveal great importance on the management of this process. Consequently, this paper aims to make an investigation related to this issue, by verifying the economic viability and profitability of PV battery systems, in several scenarios.

\section{$3 \quad$ Research Contribution}

\subsection{Methodology}

Commonly, the purpose of an economic analysis is to make an economic assessment of the viability, stability and profitability of project investment, wherein this analysis helps to reach a decision about that investment. There are some key-indicators of economic parameters that should be considered [15], as follows.

The net present value $N P V$ is defined as the sum of present values of incoming and outgoing cash flows over a period of time of the project.

$$
N P V=\sum_{j=1}^{n} \frac{R_{L j}}{(1+a)^{j}}-\sum_{j=0}^{n-1} \frac{I_{j}}{(1+a)^{j}} .
$$

Where $n$ is the project period time, $a$ the discount rate, $I_{j}$ is the investment for year $j, R_{L j}$ is the net revenue obtained for year $j$ calculated from the difference between gross revenues $R_{j}$ and maintenance and operation costs $d_{o m j}, I_{t}$ relates to the total investment. 
444 F. M. Camilo et al.

$$
R_{L j}=R_{j}-d_{o m_{j}} I_{t}
$$

The internal rate of return $I R R$ is a rate of return used in a capital expenditure budget to measure and compare the profitability of the investment.

$$
\sum_{j=1}^{n} \frac{R_{L j}}{(1+I R R)^{j}}-\sum_{j=0}^{n-1} \frac{I_{j}}{(1+I R R)^{j}}=0
$$

The discounted payback period $D P P$ is the length of time required to recover the initial investment from the present value of the expected future cash flows.

$$
\sum_{j=1}^{D P P} \frac{R_{L j}}{(1+a)^{j}}=I_{t} \Leftrightarrow D P P=\frac{\ln \left(\frac{R_{L}}{R_{L}-a I_{t}}\right)}{\ln (1+a)} .
$$

\subsection{Case Study Definition}

According to the current Portuguese legislation (Decree-Law 153/2014), the production of electricity for self-consumption is allowed with the possibility of injection of surplus to the network. Another important aspect, is that individual capacity of $\mu G$ must be less than or equal to $100 \%$ of prosumer contracted power. These legal specifications have been taken into consideration in this work.

Load and $\mu G$ data, for a typical prosumer, was estimated based on the annual profiles of consumption and $\mu G$ made available by the Portuguese Energy Services Regulatory Authority (ERSE), based on average 15 minutes intervals. On the other hand, it was assumed, based on consumption data profile, that prosumer's contracted power is $4.6 \mathrm{kVA}$, where bi-hourly tariff was selected. The average annual energy consumed per consumer is $2293 \mathrm{kWh}$.

For purposes of economic analysis of PV systems, considering the concept of selfconsumption by prosumers, eight scenarios were proposed: (i) $\mathbf{P V}$ of $0.5 \mathrm{~kW}$, where all the energy produced by PV system is used only for self-consumption; (ii) PV of 1 $\mathbf{k W}+$ net-metering, the surplus is injected in network, on net-metering format; (iii) PV of $1 \mathbf{~ k W ~ + ~ b a t t e r i e s , ~ a ~ p a r t ~ o f ~ s u r p l u s ~ i s ~ u s e d ~ t o ~ c h a r g e ~ t h e ~ b a t t e r i e s ; ~ ( i v ) ~ P V ~ o f ~}$ $1.5 \mathrm{~kW}+$ grid injection, the surplus is injected in network; (v) PV of $1.5 \mathrm{~kW}+$ netmetering, the surplus is injected in network, on net-metering format; (vi) PV of $\mathbf{1 . 5}$ $\mathbf{k W}+$ batteries, a part of surplus is used to charge the batteries; (vii) PV of $1.5 \mathrm{~kW}+$ grid injection + batteries, the surplus is used to charge the batteries and to be inject- 
ed in network; (viii) PV of 1.5 kW + net-metering + batteries, the surplus is used to charge the batteries and to be injected in network, on net-metering format.

In scenarios (iv) and (vii), is considered that the prosumers sell the surplus of energy to the network. In this context, the prosumers have to install and pay a bidirectional counter, pay a fee and get a certificate of exploitation. The remuneration $R_{m}$ of surplus (Decree-Law 153/2014) is calculated by

$$
R_{m}=E_{m} O M I E_{m} 90 \% \text {. }
$$

$R_{m}[€]$ corresponds to the remuneration of surplus energy, $E_{m}[\mathrm{kWh}]$ is the provided energy to grid, $O M I E_{m}[€ / \mathrm{kWh}]$ is the average Iberian market value, where $m$ is the month referred to electricity counting. Considering the net-metering format, the prosumers in scenarios (ii), (v) and (viii) are paid by credits.

The battery bank was sized to support only $7 \mathrm{~h}$ of consumption per day, resulting in a set of $18 \mathrm{OPzV}$ gel battery units of $2 \mathrm{~V}-220 \mathrm{Ah}$, at scenarios ((iii), (vi), (vii), (viii)). Batteries sizing was made bearing in mind the depth of discharge (DOD) and the efficiency of the energy-conversion process. Accordingly to the manufacturer, these type of battery has an approximate lifetime of 7 years, considering 2500 cycles at $35 \%$ DOD.

In the economic analysis, for the eight proposed scenarios, was considered: a period of 20 years, a discount rate of $4 \%$, a maintenance and operation costs of $1 \%$ of total investment of the project (based on $[22,23]$ ) and also a depreciation factor $D_{f}$ of $0.75 \%$ per year has been considered [24]. The $D_{f}$ factor accounts for the decrease in the efficiency of the PV panel, over its lifetime. Table 1 shows the total investment for the proposed scenarios.

Table 1. Total investment $\left(I_{t}\right)$ of PV system to eight scenarios proposed for economic analysis.

\begin{tabular}{cccccc}
\hline Scenario & $I_{t}[€]$ & Scenario & $I_{t}[€]$ & Scenario & $I_{t}[€]$ \\
\hline (i) & 1135.5 & (iv) & 3234.4 & (vii) & 14014.2 \\
(ii) & 2449.4 & (v) & 3234.4 & (viii) & 14014.2 \\
(iii) & 13027.0 & (vi) & 13477.2 & & \\
\hline
\end{tabular}

PV system values include: PV panels; micro-inverters ((i), (ii), (iv), (v)); battery bank and inverter ((iii), (vi), (vii), (viii)), where the inverter is replaced after 11 years; connecting (DC/ AC) cables structure; bidirectional meter (scenarios (ii), (iv), (v), (vii), (viii)) and the value of the installation. A tax of $23 \%$ is included on these values. 


\section{Simulation Results and Discussion}

Fig. 1 represents the average curves of the load and $\mathrm{PV} \mu \mathrm{G}$ profiles of a residential prosumer, on a summer typical day. The radiance and temperature were taken into account on PV $\mu \mathrm{G}$ profile. Self-consumption with PV $0.5 \mathrm{~kW}$ and PV $1.5 \mathrm{~kW}$ is about $78.8 \%$ and $32.1 \%$, respectively. The energy produced by PV $0.5 \mathrm{~kW}$ and PV $1.5 \mathrm{~kW}$ is approximately $800 \mathrm{kWh}$ and $2400 \mathrm{kWh}$, per year.

Fig. 2 presents the savings resulting from self-consumption, at first year of operation. The electricity bill was calculated using the present bi-hourly tariff for Portuguese electricity consumers. The first bar represents the annual electricity bill, considering that no PV system is installed. The subsequent blue bars represent the annual electricity bill considering that different PV systems are installed. The orange bars display the savings as compared to the case in which no PV system is installed. As it can be seen, each type of PV system allows a reduction of the electricity bill from network consumption. These calculations refer to the net electricity bill, no investment costs in the PV systems being considering. As is possible to perceive, PV $0.5 \mathrm{~kW}$ allows a annual reduction of $30.2 \%$, PV $1.5 \mathrm{~kW}$ of $40.4 \%$, and PV 1.5 $\mathrm{kW}+$ Batteries of $63.3 \%$.

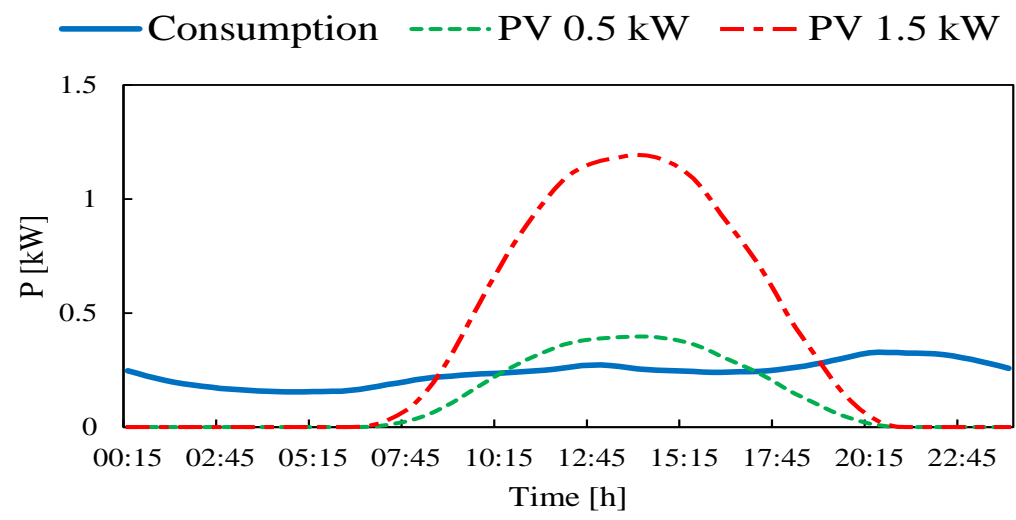

Fig. 1. Load and PV $\mu G$ profiles of a residential prosumer on a summer typical day of the year. 


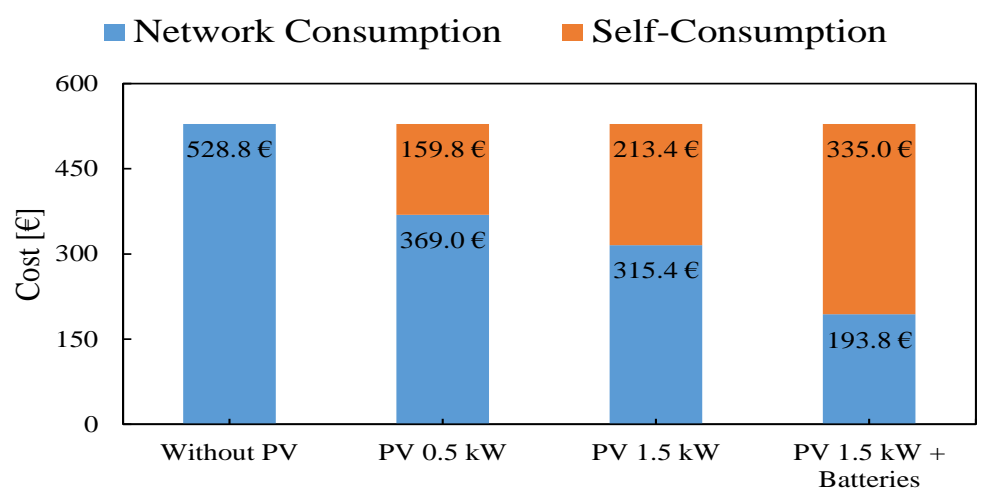

Fig. 2. The resulting savings from self-consumption, accordingly with PV system type.

Table 2 presents the economical analysis results for the eight scenarios proposed.

Table 2. The results of economic analysis.

\begin{tabular}{cccccccc}
\hline Scen. & $N P V[€]$ & $I R R[\%]$ & $D P P[$ Years $]$ & Scen. & $N P V[€]$ & $I R R[\%]$ & $D P P[$ Years] \\
\hline (i) & 807.9 & 11.2 & 9.3 & (v) & 2491.7 & 11.8 & 8.7 \\
(ii) & 1544.8 & 10.5 & 9.6 & $($ vi) & -7215.9 & -16.5 & N/A \\
(iii) & -6877.9 & -16.1 & $\mathrm{~N}^{1} \mathrm{~A}^{1}$ & $($ vii) & -7255.8 & -16.0 & N/A \\
(iv) & 267.7 & 4.9 & 16.8 & (viii) & -6065.7 & -12.7 & N/A \\
\hline
\end{tabular}

The results presented in Table 2 allow to conclude that scenarios (iii), (vi), (vii) and (viii) have a payback superior to 20 years. Contrariwise, the remaining scenarios are feasible for investment.

Currently, a PV system for self-consumption, sized to the minimum peak consumption throughout the day, avoiding the injection in network as much as possible, presents a reasonable profitable solution for the prosumer. Scenario (i), as presented in Fig. 1, comes close to this requirement. Although feasible, (iv) has a payback on a long period of time, making it unattractive as investment. This happens because, currently, the sale of electricity to the network is not economically feasible. On the other hand, the scenarios (ii) and (v) present an investment with an interesting $I R R$. It should be mentioned that was not considered any percentage penalty, relatively, to the net-metering approach.

1 Not Applicable. 
Ideally, the PV with storage allows to increase the amount of self-consumption by prosumer, as presented in Fig. 2, in comparison with a conventional PV system, without batteries. However, results of all scenarios with batteries, presented in Table 2, demonstrate that these scenarios are not profitable. This can be explained by the fact that the batteries, at present, are still expensive, although its technology has evolved. Currently, there are batteries with a long life-cycle reaching up to 5000 cycles, as lithium technology for instance. Consequently, investment on PV system with storage may become interesting, when the price of batteries decrease.

It is possible to conclude, by analyzing the results that IRR improves, if increasing the $R m$, thus making it economically, more viable and profitable for the prosumer's investment. In addition, the energy traders should encourage the prosumers with financial support, for the PV system and storage equipments. Despite the net-metering not be yet a reality in Portugal, this study revealed, in this context, that the selfconsumption with storage is feasible, being a very interesting possibility for the future.

\section{Conclusions}

An economical analysis of profitability and feasibility of PV battery systems were proposed. The main contribution of this work is to investigate, if the prosumer's investment is attractive on an economic perspective. Is essential to have a knowledge about the investment and operating costs, in order to enable timely planning and, considering the net-metering context, the on-line buying and selling of electricity where CPS can be an excellent contribution in this process.

Eight scenarios were proposed for economic analysis. The results reveal that payback of prosumer's investment can improve: if increase the $R m$, or if is on a netmetering format. On the other hand, the batteries are still expensive, despite its technology has evolved.

In future, is expected, with the prices reduction of batteries, that most of the residential PV systems will be equipped with storage. On a net-metering context, selfconsumption with storage promises to be a very feasible solution, with high potential, on an economic outlook.

Acknowledgements. This work was supported by national funds through Fundação para a Ciência e a Tecnologia (FCT) with reference UID/CEC/50021/2013.

\section{References}

1. Luque, A., Hegedus, S.: Handbook of photovoltaic science and engineering. John Wiley \& Sons (2011).

2. Rathnayaka, A.J.D., Potdar, V.M., Kuruppu, S.J.: An innovative approach to manage prosumers in smart grid. In: Sustainable Technologies (WCST), 2011. pp. 141-146 
(2011).

3. Sun, Q., Beach, A., Cotterell, M.E., Wu, Z., Grijalva, S.: An economic model for distributed energy prosumers. In: System Sciences (HICSS), 2013 46th Hawaii International Conference on. pp. 2103-2112 (2013).

4. Lampropoulos, I., Vanalme, G.M.A., Kling, W.L.: A methodology for modeling the behavior of electricity prosumers within the smart grid. In: Innovative Smart Grid Technologies Conference Europe (ISGT Europe), 2010 IEEE PES. pp. 1-8 (2010).

5. Pagani, G.A., Aiello, M.: Power grid complex network evolutions for the smart grid. Phys. A Stat. Mech. its Appl. 396, 248-266 (2014).

6. Putrus, G.A., Bentley, E., Binns, R., Jiang, T., Johnston, D.: Smart grids: energising the future. Int. J. Environ. Stud. 70, 691-701 (2013).

7. Miceli, R., Favuzza, S., Genduso, F.: A perspective on the future of distribution: Smart grids, state of the art, benefits and research plans. Energy Power Eng. 5, 36 (2013).

8. Borlase, S.: Smart Grids: Infrastructure, Technology, and Solutions. CRC Press (2012).

9. Darghouth, N.R., Barbose, G., Wiser, R.: The impact of rate design and net metering on the bill savings from distributed PV for residential customers in California. Energy Policy. 39, 5243-5253 (2011).

10. Darghouth, N.R., Barbose, G., Wiser, R.H.: Customer-economics of residential photovoltaic systems (Part 1): The impact of high renewable energy penetrations on electricity bill savings with net metering. Energy Policy. 67, 290-300 (2014).

11. Campoccia, A., Dusonchet, L., Telaretti, E., Zizzo, G.: An analysis of feed'in tariffs for solar PV in six representative countries of the European Union. Sol. Energy. 107, 530-542 (2014).

12. Forbes, I., Pearsall, N., Georgitsioti, T.: Simplified levelised cost of the domestic photovoltaic energy in the UK: the importance of the feed-in tariff scheme. IET Renew. Power Gener. 8, 451-458 (2014).

13. Eid, C., Guillén, J.R., Marín, P.F., Hakvoort, R.: The economic effect of electricity net-metering with solar PV: Consequences for network cost recovery, cross subsidies and policy objectives. Energy Policy. 75, 244-254 (2014).

14. Dusonchet, L., Telaretti, E.: Comparative economic analysis of support policies for solar PV in the most representative EU countries. Renew. Sustain. Energy Rev. 42, 986-998 (2015).

15. Baker, H.K., Powell, G.: Understanding Financial Management: A Practical Guide. Blackwell Publishing (2009).

16. Abad, F.A.T., Caccamo, M., Robbins, B.: A Fault Resilient Architecture for Distributed Cyber-Physical Systems. In: 2012 IEEE International Conference on Embedded and Real-Time Computing Systems and Applications. pp. 222-231. IEEE (2012).

17. Khaitan, S.K., McCalley, J.D.: Design Techniques and Applications of Cyberphysical Systems: A Survey. IEEE Syst. J. 9, 350-365 (2015).

18. Alippi, C.: Intelligence for Embedded Systems. (2014).

19. NIST: National Institute of Standards and Technology, http://www.nist.gov.

20. Karnouskos, S.: Cyber-physical systems in the smartgrid. In: Industrial Informatics (INDIN), 9th International Conference on. pp. 20-23. IEEE (2011).

21. Hu, F.: Cyber-Physical Systems: Integrated Computing and Eng Design. CRC Press (2013). 
450 F. M. Camilo et al.

22. Peters, M., Schmidt, T.S., Wiederkehr, D., Schneider, M.: Shedding light on solar technologies-A techno-economic assessment and its policy implications. Energy Policy. 39, 6422-6439 (2011).

23. NREL - National Renewable Energy Laboratory: Best Practices in PV System Operations and Maintenance. (2015).

24. Jordan, D., Kurtz, S.: Photovoltaic degradation rates - an analytical review. Prog. photovoltaics Res. Appl. (2013). 